NOVEL THERMAL PROPERTIES OF NANOSTRUCTURED MATERIALS*

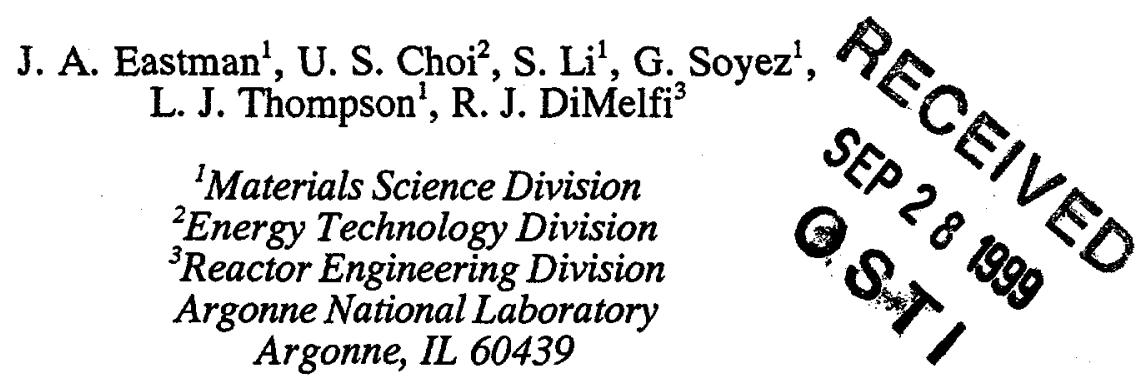

December 1998

The submitted manuscript has been created
by the University of Chicago as Operator of
Argonne National Laboratory ("Argonne'
under Contract No. W-31-109-ENG-38 with
the U.S. Department of Energy. The U.S.
Government retains for itself, and others
acting on its behalf, a paid-up, non
exclusive, irrevocable worldwide duce,
prepare derivative works, distribute copies
to the public, and perform publicly and
display publicly, by or on behalf of the
Government.

Invited paper to be submitted to the International Symposium on Metastable Mechanically Alloyed, and Nanocrystalline Materials, December 7-12, 1998, Wollongong, Australia.

\footnotetext{
${ }^{*}$ Work supported by the U.S. Department of Energy, BES-Materials Science under Contract No. W-31-109-ENG-38.
} 


\section{DISCLAIMER}

This report was prepared as an account of work sponsored by an agency of the United States Government. Neither the United States Government nor any agency thereof, nor any of their employees, make any warranty, express or implied, or assumes any legal liability or responsibility for the accuracy, completeness, or usefulness of any information, apparatus, product, or process disclosed, or represents that its use would not infringe privately owned rights. Reference herein to any specific commercial product, process, or service by trade name, trademark, manufacturer, or otherwise does not necessarily constitute or imply its endorsement, recommendation, or favoring by the United States Government or any agency thereof. The views and opinions of authors expressed herein do not necessarily state or reflect those of the United States Government or any agency thereof. 


\section{DISCLAIMER}

Portions of this document may be illegible in electronic image products. Images are produced from the best available original document. 


\title{
NOVEL THERMAL PROPERTIES OF NANOSTRUCTURED MATERIALS
}

\author{
J.A. Eastman ${ }^{1}$, U.S. Choi ${ }^{2}$, S. Li ${ }^{1}$, G. Soyez ${ }^{1}$, L.J. Thompson ${ }^{1}$, and R.J. DiMelfi ${ }^{3}$ \\ ${ }^{1}$ Materials Science Division, ${ }^{2}$ Energy Technology Division, ${ }^{3}$ Reactor Engineering Division, \\ Argonne National Laboratory, Argonne, IL, 60439 USA \\ E-mail: jeastman@anl.gov
}

Kevwords: $\quad$ thermal properties, fluids, coatings, yttria-stabilized zirconia

\begin{abstract}
A new class of heat transfer fluids, termed nanofluids, has been developed by suspending nanocrystalline particles in liquids. Due to the orders-of-magnitude larger thermal conductivities of solids compared to those of liquids such as water, significantly enhanced thermal properties are obtained with nanofluids. For example, an approximately $20 \%$ improvement in effective thermal conductivity is observed when 5 vol.\% $\mathrm{CuO}$ nanoparticles are added to water. Even more importantly, the heat transfer coefficient of water under dynamic flow conditions is increased more than $15 \%$ with the addition of less than $1 \mathrm{vol} \% \mathrm{CuO}$ particles. The use of nanofluids could impact many industrial sectors, including transportation, energy supply and production, electronics, textiles, and paper production by, for example, decreasing pumping power needs or reducing heat exchanger sizes. In contrast to the enhancement in effective thermal transport rates that is obtained when nanoparticles are suspended in fluids, nanocrystalline coatings are expected to exhibit reduced thermal conductivities compared to coarse-grained coatings. Reduced thermal conductivities are predicted to arise because of a reduction in the mean free path of phonons due to presence of grain boundaries. This behavior, combined with improved mechanical properties, makes nanostructured zirconia coatings excellent candidates for future applications as thermal barriers. Yttria-stabilized zirconia (YSZ) thin films are being produced by metal-organic chemical vapor deposition techniques. Preliminary results have indicated that the thermal conductivity is reduced by approximately a factor-of-two at room temperature in $10 \mathrm{~nm}$ grain-sized $\mathrm{YSZ}$ compared to coarse-grained or single crystal YSZ.
\end{abstract}

\section{Introduction}

While many properties of nanostructured materials such as mechanical behavior have received considerable attention in the past decade, other properties such as thermal transport have been investigated to a far lesser extent. It is well known that conventional polycrystalline materials exhibit lower thermal conductivity than low-defect single crystals of the same material. Several investigators have realized recently that this could result in significantly reduced thermal conductivities in nanostructured materials that could lead to important improvements in behavior for applications such as thermal barrier coatings. YSZ is the typical thermal barrier coating material for applications such as protecting gas turbine components in high temperature environments. While nanocrystalline YSZ has been produced in a few laboratories $[1,2]$ and has been predicted theoretically to have significantly lower thermal conductivity than coarse-grained material [3], the thermal properties have not been explored experimentally. To our knowledge, only a single experimental report of thermal conductivity in nanostructured YSZ exists [4] at this time. That study was conducted on samples prepared from sintered powders of YSZ and the results were complicated by porosity present in all samples with grain sizes below approximately $30 \mathrm{~nm}$. Our approach has been to use metal-organic chemical vapor deposition (MOCVD) processing to produce dense microstructures without elevated temperature sintering. Preliminary results from our study of nanocrystalline YSZ coatings produced by MOCVD are described below. 
Despite considerable previous research and development focusing on industrial heat transfer requirements, major improvements in heat transfer capabilities have been held back because of a fundamental limit in the thermal conductivity of conventional fluids. In contrast to the lowered thermal conductivities expected for bulk 2-D or 3-D nanocrystalline microstructures, we have recently identified an opportunity for increasing the effective thermal conductivities of liquids by dispersing nanometer-sized solid particles into conventional heating and cooling fluids such as water or ethylene glycol (forming what we call nanofluids). The thermal conductivity of heat transfer fluids plays a vital role in the development of energy-efficient heat transfer equipment. Results from our studies of the thermal conductivity and heat transfer coefficient of nanofluids are presented below.

\section{Microstructure And Properties Of Nanocrystalline Yttria-Stabilized Zirconia Coatings}

YSZ thermal barrier coatings (TBCs) are used in a number of important industrial applications, such as in protecting gas turbine components in high temperature environments. Improved TBC properties are needed for current and future applications, particularly since little progress has been made in recent years in developing new structural alloys that can be used at higher, and thus more efficient, temperatures [5,6]. Turbine component operating temperatures above $1500^{\circ} \mathrm{C}$ are desired, compared to current typical operating temperatures of $1100^{\circ} \mathrm{C}$ or below [6]. Improved thermal barrier coatings are believed to provide the best opportunity for attaining the desired higher operating temperatures [5]. Improvements in service lifetimes of components are also desirable and require the development of coatings with improved elevated temperature corrosion resistance, along with improved damage tolerances both at ambient and elevated temperatures. Attaining these goals requires the development of a new class of coatings with better adhesion properties and high densities, along with improved resistances to thermal transport. We have initiated a program to investigate the thermal and mechanical behavior of nanocrystalline YSZ coatings produced by MOCVD [7].

As seen in the plan-view TEM image shown in Fig. 1 [8], nanocrystalline YSZ coatings can be produced by MOCVD with very small grain sizes. Samples with grain sizes as small as approximately $10 \mathrm{~nm}$ and no apparent porosity have been produced on a variety of substrates including single crystal $\mathrm{Si}$ and polycrystalline $\mathrm{Ni}$ or $\mathrm{Al}_{2} \mathrm{O}_{3}$. Grain growth has been studied as a function of annealing temperature. It has been found that little grain growth occurs below $900^{\circ} \mathrm{C}$. If nanocrystalline YSZ coatings are to be used in TBC applications, stabilization of the grain size to higher temperatures will be required. One possibility for stabilizing nanocrystalline YSZ to high temperatures is to form composite microstructures, such as $\mathrm{YSZ}-\mathrm{Al}_{2} \mathrm{O}_{3}$.

The thermal conductivity of coatings can be measured in several ways. We have built a $3 \omega$ system such as that developed by Cahill and co-workers [9] to measure the thermal conductivity of our materials. This technique uses a metal line deposited onto the surface of the coating as both a heater and thermometer. The $3 \omega$ technique is particularly well-suited for measurements of the thermal conductivity of thin films, such as are produced by MOCVD. Preliminary measurements of the thermal conductivity of $10 \mathrm{~nm}$ grain-sized YSZ films indicate approximately a factor-of-two reduction in the thermal conductivity at room temperature compared to that of single crystal YSZ. This differs from the results of Raghavan et al. [4], which found no dependence of the thermal conductivity of YSZ on grain size. However, it is important to note that the phonon mean free path for YSZ calculated using a relationship derived by Debye [10] is on the order of $24 \mathrm{~nm}$ at room temperature and drops to only approximately 4 $\mathrm{nm}$ at $1800 \mathrm{~K}$. This suggests that microstructures with significantly smaller grain sizes than the $\geq 30 \mathrm{~nm}$ investigated by Raghavan et al. are required. MOCVD processing has a greater potential for producing dense coatings with the necessary small grain sizes than powder processing techniques. 


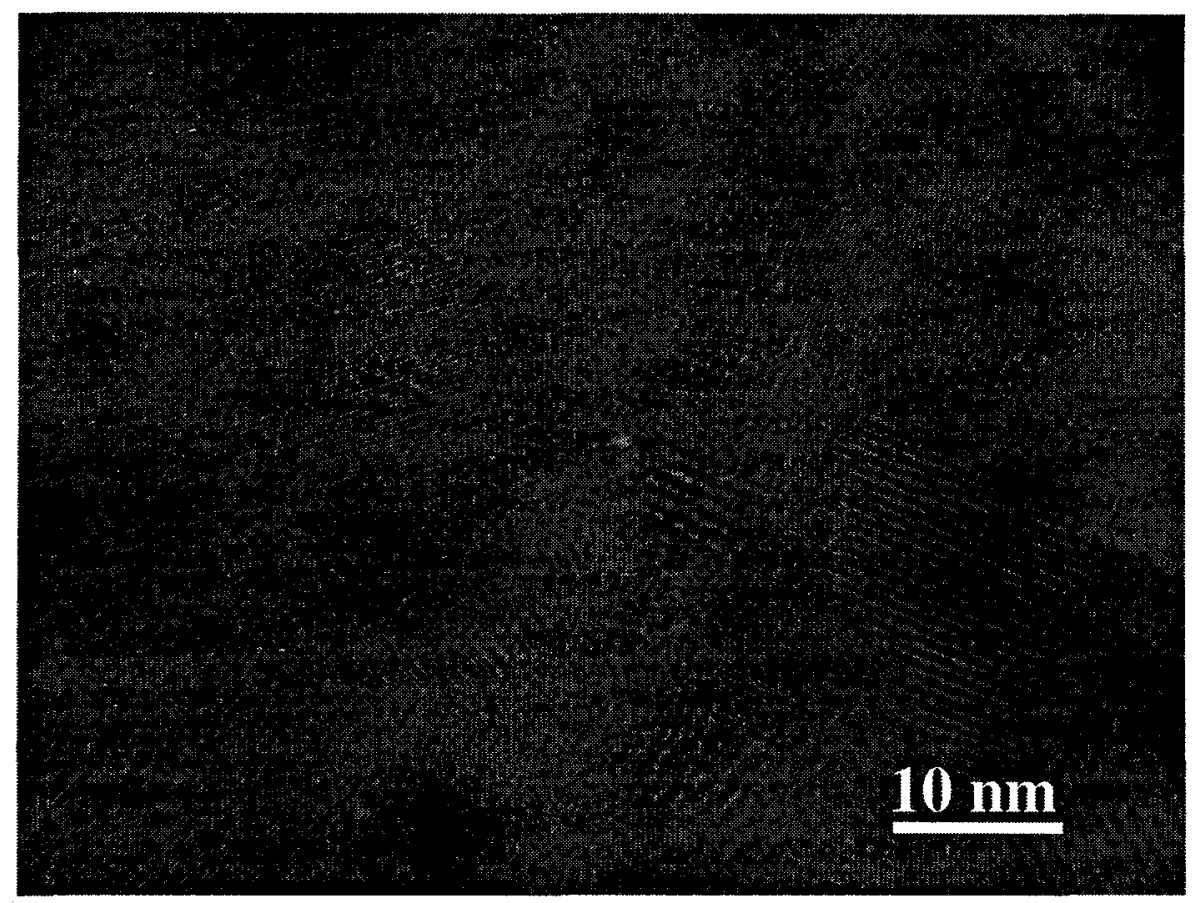

Figure 1. High resolution electron micrograph of a nanocrystalline yttriastabilized zirconia (YSZ) thin film prepared by MOCVD [8].

\section{Processing And Thermal Properties Of Nanofluids}

It is well known that metals in solid form have thermal conductivities that are higher than those of fluids by orders of magnitude. For example, the thermal conductivity of copper at room temperature is about 700 times greater than that of water and about 3000 times greater than that of engine oil. Therefore, fluids containing suspended solid metallic particles are expected to display significantly enhanced thermal conductivities relative to those of conventional heat transfer fluids.

Numerous theoretical and experimental studies of the effective thermal conductivity of dispersions containing particles have been conducted since Maxwell's theoretical work [11] was published more than 100 years ago. However, all previous studies of the thermal conductivity of suspensions have been confined to those containing millimeter- or micrometer-sized particles. Maxwell's model shows that the effective thermal conductivity of suspensions containing spherical particles increases with the volume fraction of the solid particles. It is also known that the thermal conductivity of suspensions increases with the ratio of the surface area to volume of the particles.

On the basis of these historical backgrounds and the current synthesizing technique for nanocrystalline particles, it was proposed that nanometer-sized metallic particles can be suspended in industrial heat transfer fluids such as water, ethylene glycol, or engine oil to produce a new class of engineered fluids with high thermal conductivity [12]. Our recent work has demonstrated that nanofluids exhibit significantly enhanced thermal conductivities $[13,14]$ and heat transfer coefficients [15] compared to fluids that do not contain suspended nanoparticles.

Two procedures were used in synthesizing nanofluids for this investigation. In the first, nanocrystalline powders were prepared by the gas condensation (IGC) process and then were subsequently dispersed in deionized water. Nanocrystalline $\mathrm{CuO}$ and $\mathrm{Al}_{2} \mathrm{O}_{3}$ powders [16] were 
used in these experiments. Transmission electron microscopy was used to characterize particle sizes and agglomeration behavior.

To successfully produce a nanofluid with dispersed nanocrystalline $\mathrm{Cu}$ particles, a second preparation method was used based on the vacuum evaporation onto a running oil substrate (VEROS) technique of Yatsuya et al. [17]. With this technique, nanocrystalline particles are produced by direct evaporation into a low vapor pressure liquid. Low vapor pressures are required with the VEROS technique to prevent vaporization of the liquid during the evaporation process. The system used at Argonne is based on a modification of the VEROS technique and is similar to an earlier design by Günther and co-workers at the Fraunhofer Institute for Applied Materials Research in Bremen [18]. Using this system, nanocrystalline $\mathrm{Cu}$ has been evaporated resistively into ethylene glycol. A typical micrograph of nanocrystalline $\mathrm{Cu}$ produced by this technique is shown in Fig. 2 . Note that the particle size is extremely small $(<10 \mathrm{~nm}$ average particle diameter) and there is little particle agglomeration.

Thermal conductivities were measured using a transient hot-wire apparatus described in detail in [13]. The thermal conductivities of several nanofluids are shown in Fig. 3 [14]. Thermal conductivity data are plotted normalized to the conductivity of the non-particle-containing fluids. $\mathrm{The} \mathrm{Al}_{2} \mathrm{O}_{3}$ and $\mathrm{CuO}$ data shown are for nanofluids consisting of nanoparticles dispersed in water, while the $\mathrm{Cu}$ data shown are for nanofluids dispersed in ethylene glycol. Significant increases in thermal conductivity are seen for all measured nanofluids compared to the non-particlecontaining fluid. The enhancement in thermal conductivity of nanofluids has been shown to depend on the particle size, as well as the thermal conductivity of the particle and fluid materials [14].

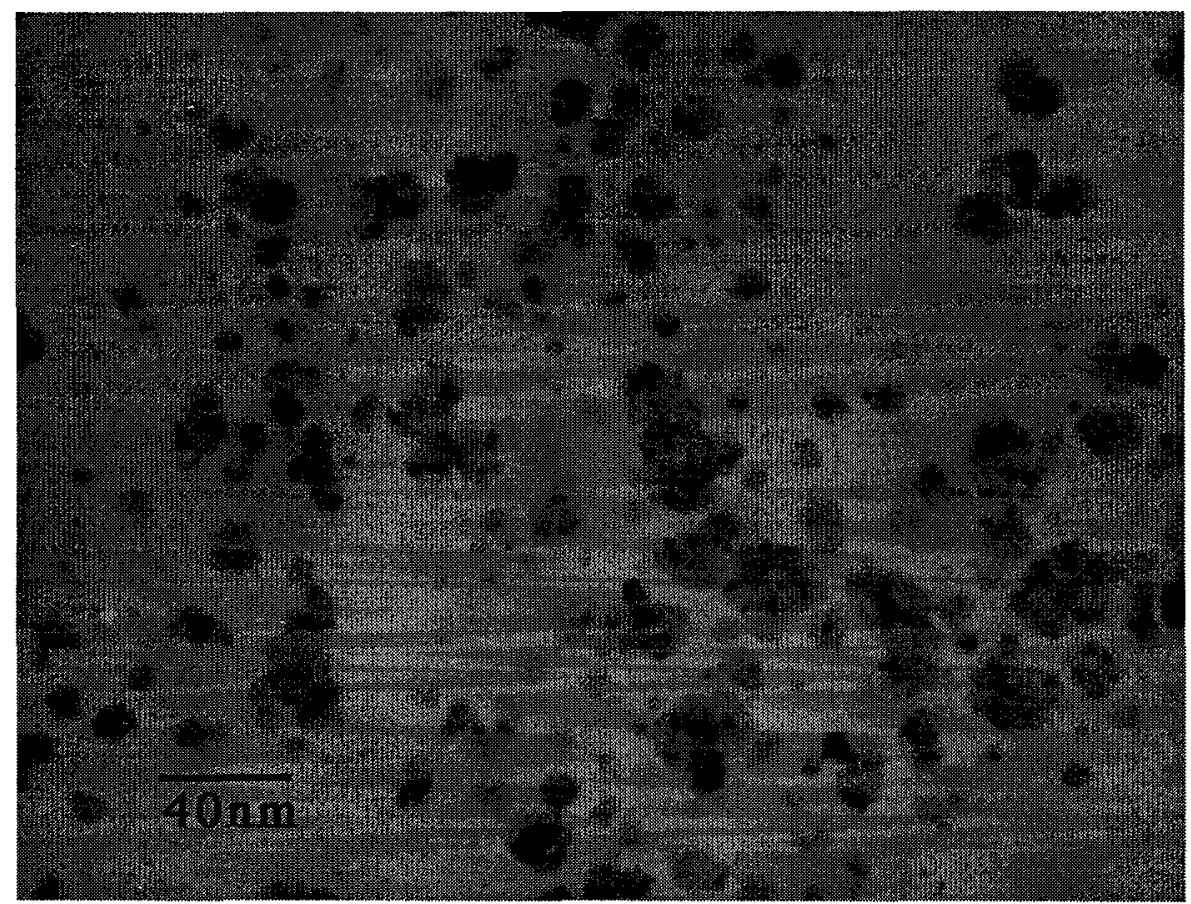

Figure 2. TEM micrograph of nanocrystalline $\mathrm{Cu}$ produced by direct evaporation into ethylene glycol. 


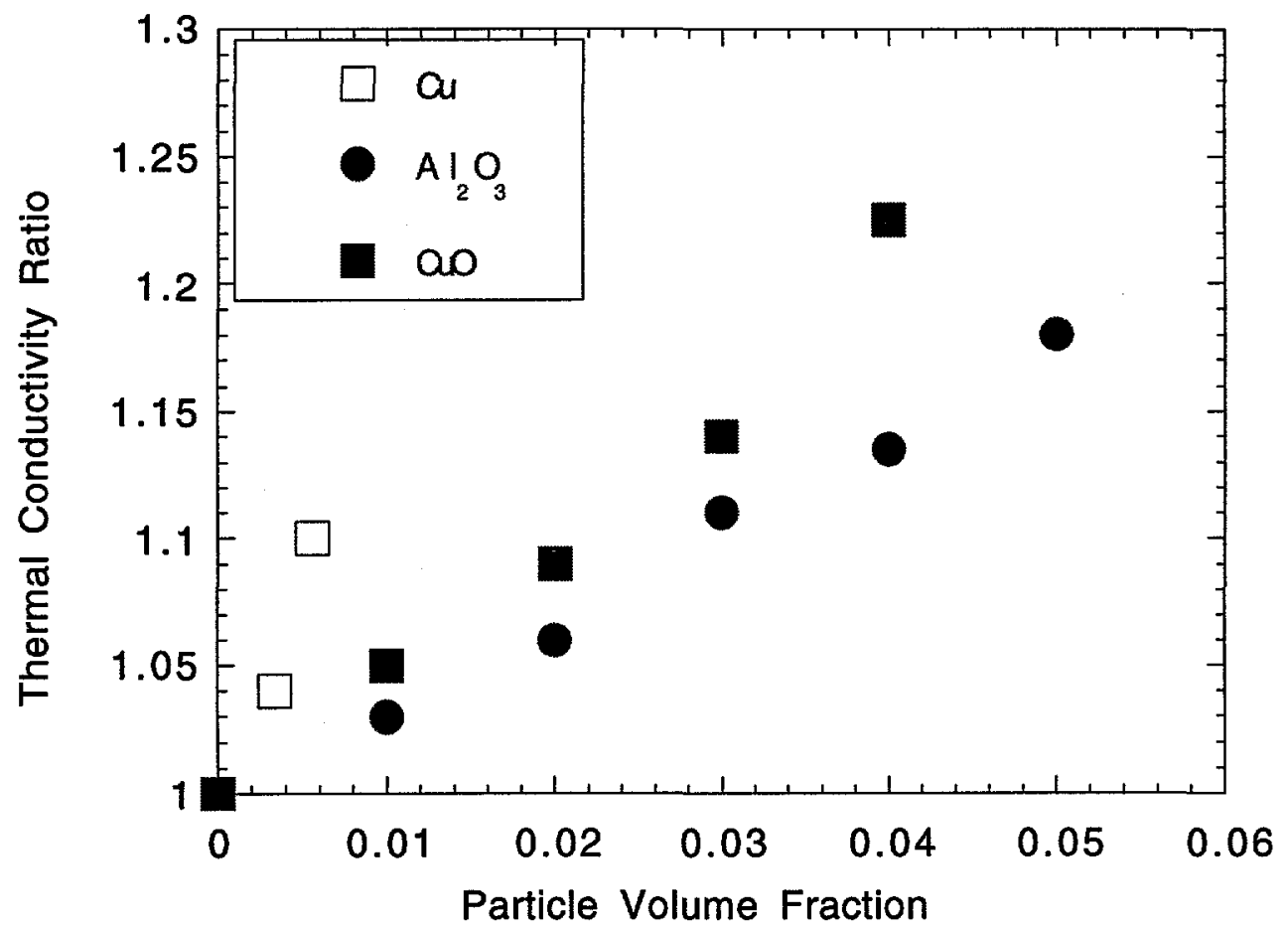

Figure 3. The enhancement in thermal conductivity of three nanofluids is shown. The $\mathrm{Cu}$ nanofluid consisted of $\mathrm{Cu}$ nanoparticles dispersed in ethylene glycol, while the two sets of oxide data are for nanoparticles dispersed in water.

In addition to measuring the thermal conductivity of several nanofluids, we have also measured the heat transfer coefficient of nanofluids under dynamic flow conditions [15]. Our data indicate that, at fixed flow rates, a greater than $15 \%$ improvement in the heat transfer coefficient of water containing less than 1 vol.\% $\mathrm{CuO}$ nanoparticles is observed, compared to that of water without nanoparticles. Likewise, these data also indicate that $\mathrm{CuO}$-in-water nanofluids can provide the same rate of heat transfer as pure water at substantially lower flow rates. This in turn would allow the use of smaller and lighter pumps in future applications using nanofluids. Applications of nanofluids can be considered for a wide variety of industries ranging from transportation, HVAC, energy production and supply, to electronics, textiles, and paper production.

\section{Acknowledgments}

This work was supported by the U. S. Department of Energy, BES-DMS, under Contract W-31109-Eng-38 and by grants from Argonne's Coordinating Council for Science and Technology. 


\section{References}

[1] G. Theunissen, A. Winnubst, and A. J. Burggraaf, J. Eur. Ceram. Soc., 11, 315 (1993).

[2] M.J. Mayo, Int. Mat. Rev., 41, 85 (1996).

[3] P.G. Klemens, in Chemistry and Physics of Nanostructures and Related Non-Equilibrium Materials, (TMS: Warrendale, PA), 97-104 (1997).

[4] S. Raghavan, H. Wang, R.B. Dinwiddie, W.D. Porter, and M.J. Mayo, Scripta Mater., 39, no. 8, 1119-1125 (1998).

[5] W.P. Parks, W.Y. Lee, and I.G. Wright, Proceedings of the Thermal Barrier Coating Workshop, Westlake, OH, DOE Report Conf-9503150-1 (1995).

[6] G.A. Kool, J. Thermal Spray Technol., 5, no. 1, 31-34 (1996)

[7] G. Soyez, J.A. Eastman, R.J. DiMelfi, and L.J. Thompson, unpublished.

[8] Z. Li, K.L. Merkle, G.-R. Bai, C.F. Foster, and J.A. Eastman, unpublished.

[9] D.G. Cahill, S.K. Watson, and R.O. Pohl, Phys. Rev. B, 46, no. 10, 6131 (1992).

[10] G.H. Geiger and D.R. Pourier, "Transport Phenomena in Metallurgy," (Addison-Wesley: Reading, MA), 1973.

[11] J.C. Maxwell, "A Treatise on Electricity and Magnetism," 2nd Ed., Vol. 1, p. 435, Clarendon Press (1881).

[12] U.S. Choi, in "Developments and Applications of Non-Newtonian Flows," eds. D.A. Siginer and H.P. Wang, (ASME: New York), FED-Vol. 231/MD-Vol. 66, 99 (1995).

[13] S. Lee, U.S. Choi, S. Li, and J.A. Eastman, accepted for publication in J. Heat Transfer (1998).

[14] J.A. Eastman, S. Li, and U.S. Choi, in preparation.

[15] U.S. Choi, S. Li, and J.A. Eastman, in preparation.

[16] Nanophase Technologies Corporation, Burr Ridge, IL.

[17] S. Yatsuya, Y. Tsukasaki, K. Mihama, and R. Uyeda, J. Cryst. Growth, 43, 490 (1978).

[18] M. Wagener, B.S. Murty, and B. Günther, in "Nanophase and Nanocomposite Materials II," ed. S. Komareni, J.C. Parker, and H.J. Wollenberger, MRS Proceedings, 457, 149 (1997). 